\title{
Mosquito-Associated Viruses in China
}

\author{
Han Xia ${ }^{1} \cdot$ Yujuan Wang ${ }^{1,2} \cdot$ Evans Atoni $^{1,2} \cdot$ Bo Zhang $^{1} \cdot$ Zhiming Yuan $^{1}$
}

Received: 7 June 2017 / Accepted: 5 December 2017 / Published online: 12 March 2018

(C) The Author(s) 2018. This article is an open access publication

\begin{abstract}
Mosquitoes are classified into approximately 3500 species and further grouped into 41 genera. Epidemiologically, they are considered to be among the most important disease vectors in the world and they can harbor a wide variety of viruses. Several mosquito viruses are considered to be of significant medical importance and can cause serious public health issues throughout the world. Such viruses are Japanese encephalitis virus (JEV), dengue virus (DENV), chikungunya virus (CHIKV), and Zika virus (ZIKV). Others are the newly recognized mosquito viruses such as Banna virus (BAV) and Yunnan orbivirus (YNOV) with unclear medical significance. The remaining mosquito viruses are those that naturally infect mosquitoes but do not appear to infect humans or other vertebrates. With the continuous development and improvement of mosquito and mosquito-associated virus surveillance systems in China, many novel mosquito-associated viruses have been discovered in recent years. This review aims to systematically outline the history, characteristics, distribution, and/or current epidemic status of mosquito-associated viruses in China.
\end{abstract}

Keywords Mosquito associated viruses $\cdot$ China $\cdot$ Vector $\cdot$ Public health

\section{Introduction}

Mosquitoes are small insects that are taxonomically classified into the family Culicidae. There are approximately 3500 species of mosquito in the world, grouped into 41 genera. Mosquitoes carry a wide variety of viruses, and these viruses can be classified into two categories: mosquito-borne viruses and mosquito-specific viruses. Mosquito-borne viruses are arboviruses, which can replicate within the mosquito but can also be transmitted biologically to vertebrates and infect vertebrate cells. Most of the mosquito-borne viruses are pathogenic viruses responsible for disease outbreaks in human and animal populations, such as dengue virus (DENV), chikungunya virus (CHIKV), yellow fever virus (YFV), Zika virus (ZIKV), and Akabane virus (AKV). The majority of mosquito-

Han Xia and Yujuan Wang have contributed equally to this work.

Zhiming Yuan

yzm@wh.iov.cn

1 Key Laboratory of Special Pathogens and Biosafety, Wuhan Institute of Virology, Chinese Academy of Sciences, Wuhan 430071, China

2 University of Chinese Academy of Sciences, Beijing 100049, China borne viruses are distributed within the families Peribunyaviridae, Flaviviridae, Togaviridae, and Reoviridae. Mosquito-specific viruses, as insect-specific viruses (ISVs), can infect mosquitoes naturally and replicate in mosquito cells in vitro, but do not replicate in vertebrate cells or infect humans or other vertebrates (Bolling et al. 2015). These viruses are distantly related to known pathogenic viruses and are found within the families Parvoviridae, Flaviviridae, Togaviridae, Rhabdoviridae, Peribunyaviridae, Reoviridae, Mesoniviridae, Tymoviridae, and Birnaviridae.

With the development and improvement of mosquito and mosquito-associated virus surveillance systems in China, many novel mosquito-associated viruses have been discovered and identified in recent years. This review briefly summarizes the present knowledge about the mosquito-associated viruses in mainland China (Table 1). 


\section{Mosquito-Borne Viruses Pathogenic to Humans or Animals}

\section{Flaviviridae}

\section{Dengue virus (DENV)}

DENV is a member of the genus Flavivirus, family Flaviviridae. It is related to other medically important arboviruses such as YFV and Japanese encephalitis virus (JEV).

DENV was first isolated from human blood samples in Japan, in the year 1943 (Messina et al. 2014). Since then, four phylogenetically and antigenically distinct DENVs (DENV1-4) have been identified. In China, all four serotypes of DENV have caused dengue outbreaks. DENV-1 has been the primary epidemic serotype since the 1990s (Lai et al. 2015; Xiong and Chen 2014). DENV-4 was the first documented serotype in Guangdong in 1978, with a second DENV-4 outbreak occurring in 1990. In the year 2010, after an absence of almost 20 years, DENV-4 was again detected during an outbreak in Guangzhou and initially traced back to an imported case: a Guangzhou resident who had traveled back home from Thailand (Jing et al. 2012). DENV-3 was recorded in Hainan in 1980. Later, DENV-3 was also isolated in outbreaks in Guangdong in 2009 and 2010, Zhejiang in 2009 (Yan et al. 2010), and Yunnan and Henan in 2013 (Huang et al. 2014; Zhang et al. 2014). DENV-2 was confirmed in Hainan in 1985-1987, and a few cases were reported in 2013 and 2014 (Lai et al. 2015; Xiong and Chen 2014).

DENV is carried and spread by mosquitoes of the genus Aedes and mainly through Aedes aegypti, which is active in the living spaces of humans. Aedes aegypti and Aedes albopictus are the primary vectors of DENV in China. Imported DENVs may infect the vector population during permissive climatic conditions (Wu et al. 2010).

Symptoms for DENV infection typically include a high fever, headache, vomiting, muscle and joint pains, and skin rash. In a small proportion of cases, the disease develops into a serious dengue hemorrhagic fever/dengue shock syndrome (DHF/DSS) resulting in high mortality (Heilman et al. 2014). Currently, there is no US Food and Drug Administration (FDA)-approved vaccine or antiviral treatment specifically for dengue. In China, during 1978-1991, the epidemic regions were mainly in Guangdong and Hainan. After 1990, the endemic range of dengue fever in China expanded geographically, with the new cases being reported in Guangxi, Fujian, Zhejiang, Jiangsu, Yunnan, Henan, Hubei, and Beijing. In 2013, the first dengue fever outbreak in central China occurred in Henan province (Wang W et al. 2015; Zhang et al. 2014). These outbreaks of dengue fever in China are suspected to result from virus imported by infected travelers coming from dengueendemic regions or local epidemics initiated by imported cases. Recently, dengue fever has shown an increasing drift especially in the four main hotspot areas, namely Guangdong, Fujian, Zhejiang, and more recently Yunnan (Gu et al. 2012; Sun et al. 2011; Yan et al. 2010; Yang et al. 2015; Zhang et al. 2014; Zhao et al. 2016). According to the China National Notifiable Disease Surveillance System, from the year 2002-2016, the incidence ranged from 0.01 to 3.46 per 100,000 people, with a total of seven deaths reported. In the year 2014, there were more than 44,000 reported cases of dengue fever, which stands out as the highest ever number of dengue infections per year in the historical records.

\section{Japanese encephalitis virus (JEV)}

JEV is a member of the Japanese encephalitis (JE) serogroup of the genus Flavivirus, family Flaviviridae. The prototype Nakayama strain was first isolated in 1953 from the brain of a fatal case and has subsequently been found across most parts of Asia (Solomon et al. 2000). JEV was first isolated from human brain (strains A2 and P3) in China in the 1940s, and since then JE epidemics have occurred in China for over 60 years (Wang et al. 2007, Wang HY et al. 2009). Phylogenetic analyses based on the E region divides JEV into five genotypes (Gao et al. 2015; Solomon and Ni 2003; Wang et al. 2007). Molecular biological research has indicated that the JEV strains isolated in China are mainly divided into two genotypes: genotypes 1 and 3. Genotype $1 \mathrm{JEV}$ strains have been isolated since 1979, while genotype $3 \mathrm{JEV}$ strains have been isolated since the 1940s, and genotype 1 has gradually been replacing genotype 3 as the dominant genotype in the JE outbreaks during the last decade (Gao et al. 2015; Wang et al. 2007, Wang HY et al. 2009). One strain of genotype 5 JEV (strain XZ0934) was isolated from Culex tritaeniorhynchus collected in Tibet in 2009 (Li et al. 2011).

JEV has a zoonotic transmission cycle between mosquitoes and vertebrate hosts. Culex tritaeniorhynchus is the most important vector for JEV in China. However, other mosquito species have also been implicated as vectors of $\mathrm{JEV}$, such as Aedes vexans, Culex modestus, Culex pipiens pallens, Culex theileri, Anopheles sinensis, and Armigeres subalbatus (Wang et al. 2007). In nature, the virus cycle is maintained between mosquitoes and vertebrate hosts such as bats, water birds, and pigs.

The human disease caused by JEV results in inflammation of the brain, with other symptoms including high fever, coma, tremors, and convulsions. The mortality rate is 5\%-40\% (Misra and Kalita 2010). Occurrence and epidemic outbreaks of JEV have been reported in all provinces of mainland China except Xinjiang, Tibet, and Qinghai. 


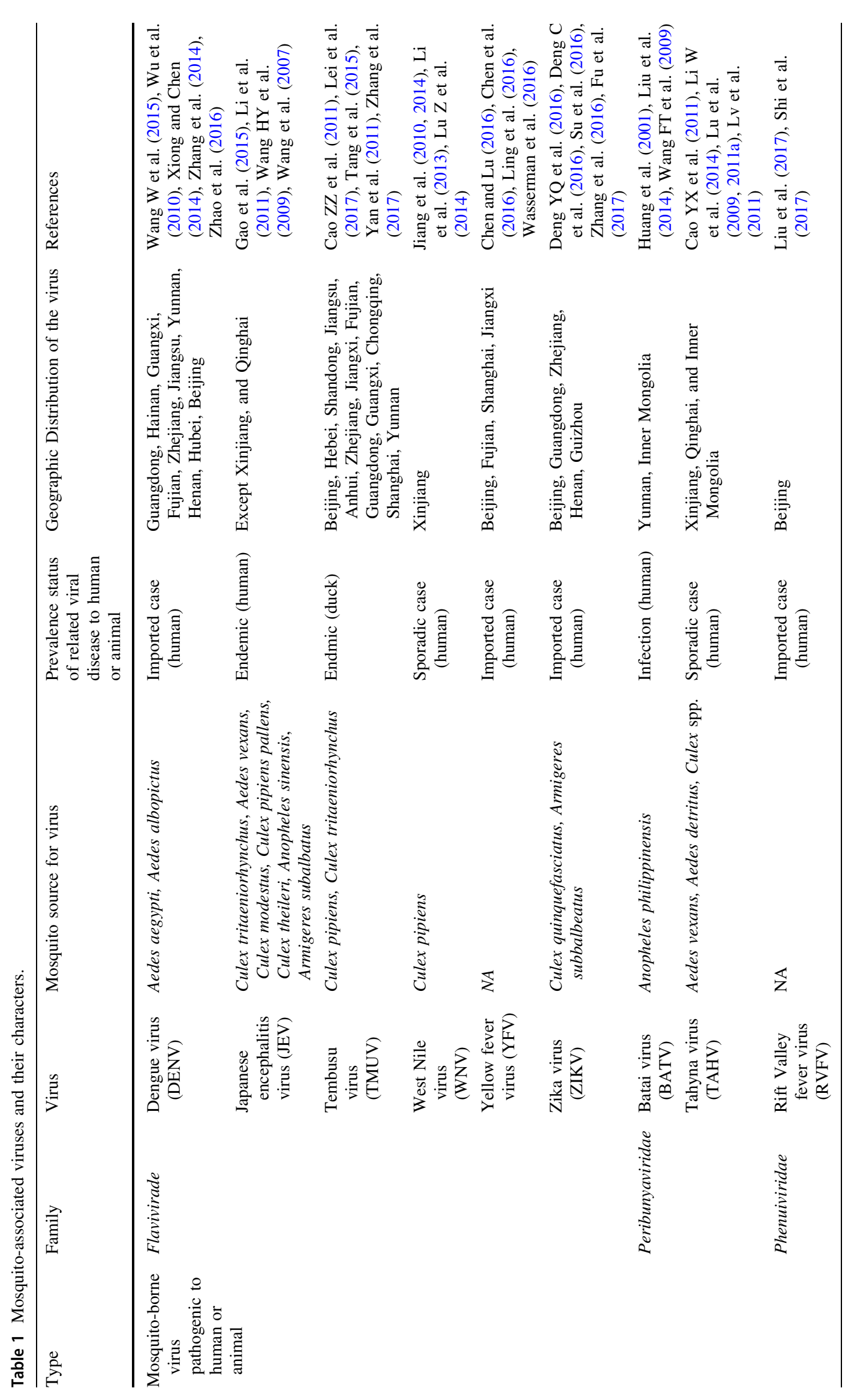




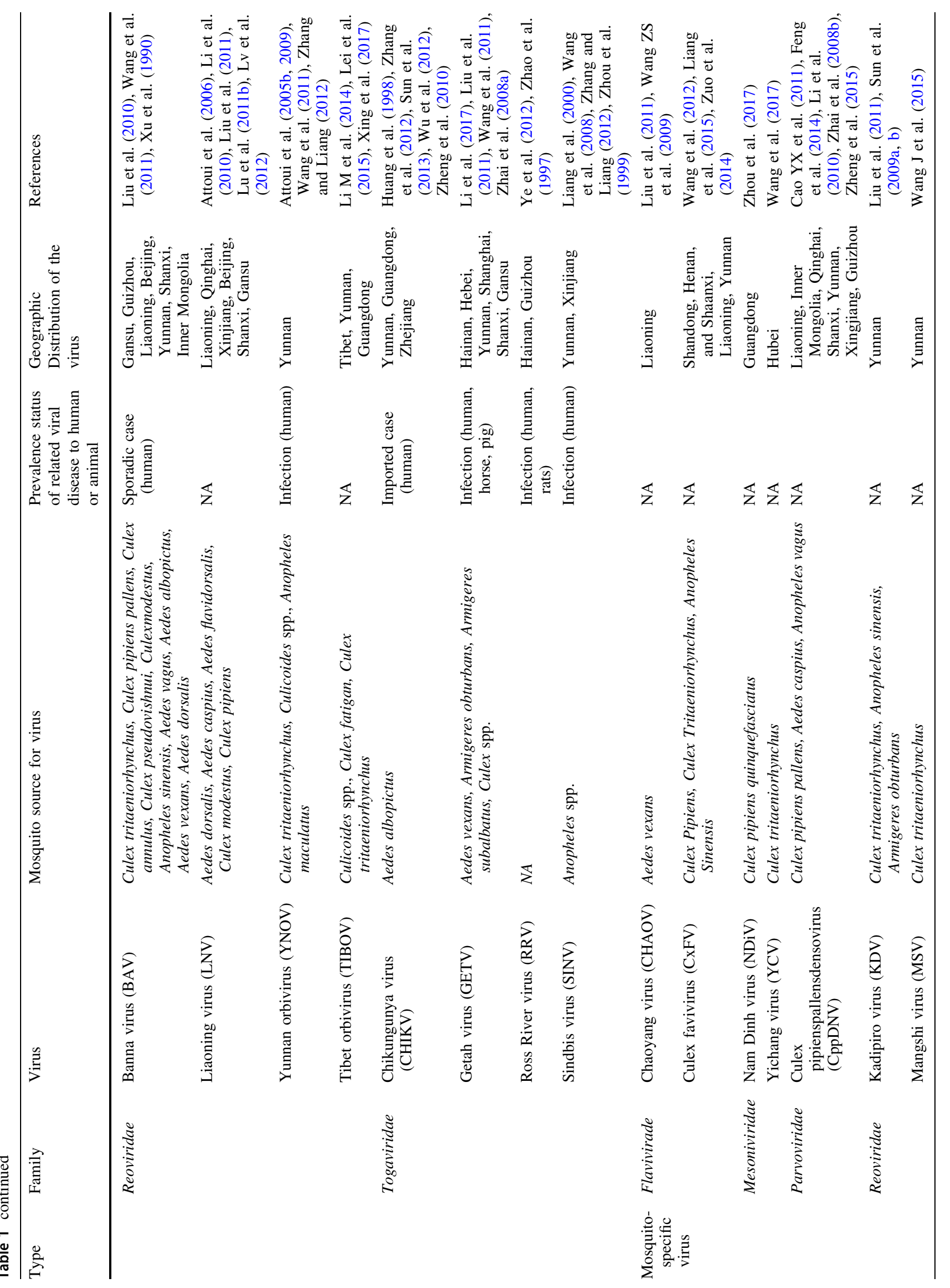


Based on seasonal distribution, JE cases in the south tend to increase during the month of July and decrease significantly in August, whereas in the north, they begin to increase in the month of August and dramatically decrease in September (Wang HY et al. 2009). The highly endemic areas (with average incidence $>1 / 100,000$ ) include Sichuan, Guizhou, Chongqing, Shaanxi, and Yunnan, which are located in southwest and central China and adjacent to each other. The moderately endemic regions (with average incidence of between 0.5/100,000 and 1/100,000) include Shanxi, Henan, Anhui, Hubei, Hunan, Jiangxi, and Guangxi (Wang HY et al. 2009). A large epidemic of JE occurred in the 1960s and early 1970s, and a total of 170,000 cases were reported with incidence rates of 20/100,000 people and a fatality rate of $25 \%$ (Gao et al. 2010). The development of a JE live attenuated vaccine (SA14-14-2) in 1989 and its expansive use thereafter has seen the number of JE cases, especially the fatal cases, reduced significantly. For instance, the incidence rates from 2002 to 2016 remained at 1/100,000 people.

\section{Tembusu virus (TMUV)}

TMUV is a member of the Ntaya virus serogroup in the genus Flavivirus, family Flaviviridae. TMUV was first isolated in 1955 from Culex tritaeniorhynchus mosquitoes in Kuala Lumpur, Malaysia. Since then, it has been successively isolated from mosquitoes (Culex spp.) and a variety of avian species including ducks, geese, chickens, pigeons, and sparrows in Southeast Asia or China (Zhang et al. 2017). In China, it was first isolated from ducks in an outbreak of duck egg-drop disease in 2010 (Cao ZZ et al. 2011; Yan et al. 2011). Phylogenetic analysis indicated that TMUV did not exhibit a species barrier in avian species and consisted of two lineages: the Southeast Asian and the Chinese lineages (Lei et al. 2017).

In nature, the cycle for TMUV-mosquito-avian transmission remains unclear. However, vector competence tests showed that field-caught mosquitoes can be efficient vectors for spreading the virus (O'Guinn et al. 2013). The detection and isolation of TMUV from mosquitoes (Culex pipiens and Culex tritaeniorhynchus) in China was reported in Shandong and Yunnan provinces, and the results showed a high percentage of positives for TMUV by both RT-PCR and virus isolation assays (Lei et al. 2017; Tang et al. 2015).

TMUV-associated diseases in animals have been noted in China and Malaysia, such as encephalitis and retarded growth in broiler chicks (Kono et al. 2000) and duck eggdrop disease (Cao ZZ et al. 2011; Yan et al. 2011). In China, since 2010, duck egg-drop disease has been reported in most duck-producing regions, including Beijing, Hebei, Shandong, Jiangsu, Anhui, Zhejiang, Jiangxi, Fujian, Guangdong, Guangxi, Chongqing, and Shanghai (Zhang et al. 2017). In addition, a serological survey in Shangdong suggested there were human infections by TMUV, but there are no current reports of human disease related to TMUV (Tang et al. 2013).

\section{West Nile virus (WNV)}

WNV is a member of the genus Flavivirus, family Flaviviridae. WNV was first isolated in a woman in the West Nile district of Uganda in 1937. Since then, it has been detected in Africa, Asia, Europe, Australia, and North America (Chancey et al. 2015). In China, WNV was first isolated from Culex pipiens mosquitoes in Xinjiang in 2011. The Xinjiang WNV isolates showed a high degree of genetic similarity to lineage 1 containing other highly pathogenic WNV strains ( $\mathrm{Lu} \mathrm{Z}$ et al. 2014).

In nature, WNV cycles between mosquitoes and birds, and almost 75 mosquito species have been identified as WNV vectors (mainly the Culex species), with different species recognized as primary vectors in different areas (Rossi et al. 2010). Humans, horses, and other mammals can be infected through mosquito bites. In addition, four species of Culex mosquitoes found in China were determined to be competent laboratory vectors of WNV (Jiang et al. 2010, 2014).

Most people infected with WNV develop a fever with other symptoms such as headache, body aches, joint pains, and vomiting, and less than $1 \%$ of people will develop a serious neurologic disease such as encephalitis or meningitis (Chancey et al. 2015; Rossi et al. 2010). Currently, no vaccine or specific antiviral treatments for WNV infection are available. In China, seropositivity for WNV was first reported in birds from Yunnan province in 1988. Serological evidence was also reported in cats, dogs, and captive resident birds in Shanghai in 2010 (Lan et al. 2011). The first confirmed human cases of WNV in China were reported in 2013 during an outbreak of fever and meningitis/encephalitis in Xinjiang in 2004 (Li et al. 2013). Since then, no new cases of WNV in China have been reported. Subsequently, evidence of WNV human infections was confirmed by IgM ELISA and seroconversion by $90 \%$ plaque reduction neutralization test of paired serum samples obtained from persons with febrile illness and viral encephalitis in Xinjiang in 2004 (Lu Z et al. 2014). Even though reported WNV cases have been limited in Xingjiang until now, it is possible that migrating birds and the domestic animal trade could introduce WNV from endemic regions to China or induce local transmission in China.

\section{Yellow fever virus (YFV)}

YFV is the prototype virus of the genus Flavivirus, family Flaviviridae, which causes yellow fever with symptoms 
ranging from mild, non-specific febrile illness to a severe acute disease with hemorrhage, vomiting, renal failure, and severe hepatic dysfunction in humans (Monath and Vasconcelos 2015). YFV was first isolated in 1927 from a Ghanaian patient named Asibi in West Africa. YFV is known to be widely distributed in tropical regions of Africa and South America (Jentes et al. 2011; Monath and Vasconcelos 2015). YFV can be transmitted to humans and non-human primates through mosquito bites. Aedes aegypti is the only vector in the "urban cycle" known to be responsible for the major outbreaks of yellow fever in Africa. In the sylvatic "jungle cycle", monkeys act as the host and Aedes africanus and other Aedes spp. are the vectors (Chen and $\mathrm{Lu} 2016$ ).

No YFV isolate or yellow fever case was reported in China before 2016 (Wasserman et al. 2016). In China, YFV was first (strain CNYF01/2016) isolated from the first imported case in Beijing in 2016. Phylogenetic analysis showed the strain belongs to the Angola71 genotype, which has only 14 amino-acid substitutions throughout the genome and no amino-acid changes observed in the membrane or envelope proteins compared with the YFV strain collected in 1971 (Chen et al. 2016). By the end of 2016, there were a total of 11 confirmed imported cases of yellow fever, of which five were identified in Beijing, another five cases were reported in Fujian, and one case was identified in Shanghai (Ling et al. 2016; Wasserman et al. 2016). All the patients had traveled back to China from Angola. Although no local case of yellow fever has been reported, with the growing migration in southern China, where the Aedes aegypti density is relatively high, there is an increased risk of autochthonous transmission in this region (Chen and Lu 2016). The main strategies for control of yellow fever transmission in China entail continuous screening, control of vectors, vaccination of travelers that are going to yellow fever endemic regions, and strengthening of public education.

\section{Zika virus (ZIKV)}

ZIKV belongs to the genus Flavivirus, family Flaviviridae. It was first isolated in 1947 from a rhesus monkey in Zika Forest, Uganda. Human infections with Zika virus (ZIKV) usually present mild symptoms such as fever, skin rashes, muscle and joint pain, and headache. But recently, the infection was reportedly associated with microcephaly in infants and neurological disorders such as Guillain-Barré syndrome (GBS) (Rasmussen et al. 2016; Zanluca et al. 2016). ZIKV had limited circulation in Africa, Southeast Asia, and the Pacific prior to the year 2015. Since then, it has rapidly spread to more than 30 countries in Africa, the Americas, Asia, and the Pacific (Bogoch et al. 2016). ZIKV is classified into two major lineages, the African and Asian lineages. Aedes aegypti and Aedes albopictus are the two major mosquito vectors responsible for ZIKV transmission.

The first Chinese ZIKV strain was isolated from an imported case in Shenzhen in 2016 (Deng C et al. 2016; Deng YQ et al. 2016). By the end of 2016, a total of 22 ZIKV disease cases were reported in China, 14 cases in Guangdong, two cases in Beijing, four cases in Zhejiang, one case in Henan, and one case in Jiangxi. All these patients had recent travel history to South America or Oceania (Zhang et al. 2016). Seven available Chinese imported ZIKV sequences cluster within the Asian lineage, separated into three groups, and demonstrate a high genetic diversity. Since the Aedes mosquitoes are broadly distributed in southern China, where warm weather and precipitation are ideal for promoting the population growth of Aedes, the risk of imported ZIKV spreading within these regions is increasing ( $\mathrm{Su}$ et al. 2016). In addition, two ZIKV strains were isolated from Culex quinquefasciatus and Armigeres subbalbeatus respectively in a survey in Guizhou province, in August, 2016 (Fu et al. 2017). Phylogenetic analyses indicated that the strains (GZDJ1685) from Culex quinquefasciatus was clustered into the Asian branch along with isolates from Brazil (2015), Puerto Rico (2015), and Yap Island (2007) (Song et al. 2017). This is the first report of ZIKV isolation in nature in China and presents new challenges for the prevention and control of ZIKV in China (Fu et al. 2017; Song et al. 2017).

\section{Peribunyaviridae}

\section{Batai virus (BATV)}

BATV is a member of the Bunyamwera group in the genus Orthobunyavirus, family Peribunyaviridae. BATV was originally isolated (MM-2222) from Culex gelidus collected in Malaysia in 1955 (Karabatsos 1978). BATV is widely distributed throughout large parts of Africa, Asia, and Europe. In China, BATV (strain YN92-4) was first isolated from an Anopheles philippinensis mosquito found in Yunnan in 1988 (Wang FT et al. 2009). In 2012, BATV (strain NM/12) was isolated from cattle in Inner Mongolia (Liu et al. 2014). Phylogenetic analyses based on the S, M, and L segments revealed that the YN92-4 strain belongs to the same group as the MM-2222 strain isolated in Malaysia (Wang FT et al. 2009), and the NM/12 strain is closely related to strains found in different regions of Asia and distantly related to European BATV strains (Liu et al. 2014).

BATV is transmitted by the mosquitoes Anopheles maculipennis s.l., Anopheles claviger, and Ochlerotatus spp. The vertebrate hosts of BATV include domestic pigs, horses, ruminants, and wild birds (Bialonski et al. 2011; Huhtamo et al. 2013; Liu et al. 2014). 
Human infection by BATV shows symptoms of selflimiting influenza-like febrile illness. In addition, BATV has been implicated as a segment donor in the generation of the reassortant Ngari virus which caused outbreaks of hemorrhagic illness in East Africa (Briese et al. 2006; Liu et al. 2011). A sero-survey in Xishuangbanna in Yunnan showed that the positive rate of BATV specific antibody was $4.7 \%(5 / 120)$ in febrile patients, giving evidence of BATV infection in this locality (Huang et al. 2001).

\section{Tahyna virus (TAHV)}

TAHV is a member of the California antigenic group in the genus Orthobunyavirus, family Peribunyaviridae (Hubálek 2008; Lu et al. 2009). TAHV was originally isolated (prototype strain T-92) from a pool of Aedes caspius mosquitoes in eastern Slovakia in 1958 (Hubálek 2008). TAHV occurs in Asia, Africa, and Europe. In China, it was first isolated (strain XJ0625) from Culex spp. in Kashi, Xinjiang, in 2006 (Lu et al. 2009). Subsequently, TAHV has been isolated from Xinjiang, Qinghai, and Inner Mongolia (Cao YX et al. 2011; Li W et al. 2014; Lu et al. 2011a). Phylogenetic analysis generated from N segment and polymerase gene sequences indicated that all TAHV isolates from China group together. However, the analysis for the M segment showed the isolate XJ0708 aligns independently within the context of a relatively large diversity of isolates from Europe ( $\mathrm{Lu}$ et al. 2011a).

TAHV is maintained in several species of mosquito vectors and vertebrates such as hares, rabbits, hedgehogs, and rodents. In China, TAHV has been isolated from Aedex vexans, Aedes detritus, and Culex spp. (Li W et al. 2014; Lu et al. 2009, 2011a).

The human disease caused by TAHV is an influenza-like illness with a sudden onset of fever, or pneumonia, acute arthritis, and rarely meningoencephalitis. Currently, no mortality has been reported as a result of TAHV infection. TAHV antibodies (IgG) have been detected in serum from fever and headache patients in Jiashi County in Xinjing with a $13.0 \%$ positive rate, and in local livestock in Geermu city in Qinghai (Li W et al. 2014; Lu et al. 2009; Lv et al. 2011). In 2009, confirmed cases of TAHV were reported for the first time in Qinghai (Li W et al. 2014).

\section{Phenuiviridae}

\section{Rift Valley fever virus (RVFV)}

RVFV is the member of genus Phlebovirus, family Phenuiviridae. The RVFV genome ( $\sim 12 \mathrm{~kb})$ consists of three negative-stranded RNA, designated large (L), medium (M) and small (S) segment, and the viruses can be classified into seven major genetic lineages (Pepin et al.
2010; Fu et al. 2016). RVFV could cause high levels of mortality and morbidity in domesticated animals and mild to serious disease in humans. RVFV was first isolated from sheep in Kenya in 1930s, subsequently it is present or endemic in Africa, Saudi Arabia and Yemen.

The main vectors of RVFV transmission are the mosquitoes in the genera of Aedes spp. and Culex spp., and the outbreaks of Rift Valley fever are strong correlated with heavy rainfall or flooding (Pepin et al. 2010; Fu et al. 2016).

Recently, the first imported case of Rift Valley fever was confirmed China on 23 July, 2016. The patient was a 45-year-old male who returned from Angola and arrived in Beijing Capital International Airport. The RVFV was isolated from the patient's blood, and the whole-genome sequencing and phyleogenetic analysis indicated that the imported strain was a reassotant comprising the $\mathrm{L}$ and $\mathrm{M}$ segments from lineage $\mathrm{E}$ and the $\mathrm{S}$ segment from lineage $\mathrm{A}$ (Liu et al. 2017; Shi et al. 2017).

\section{Reoviridae}

\section{Banna virus (BAV)}

BAV is the prototype species of the genus Seadornavirus that includes Kadipiro virus (KDV) and Liaoning virus (LNV) within the family Reoviridae (Attoui et al. 2000, 2005b; Liu et al. 2010). The BAV genome is around $21 \mathrm{~kb}$, which consists of 12 segments of double-stranded RNA (dsRNA) (Liu et al. 2010). BAV (strain BAV-Ch) was originally isolated from a patient with encephalitis and fever in Yunnan, China, in 1987 (Xu et al. 1990). BAV is widely distributed in China (Gansu, Liaoning, Beijing, Yunnan, Shanxi, Inner Mongolia) and Southeast Asia (Indonesia, Vietnam) (Liu et al. 2010; Nabeshima et al. 2008; Wang et al. 2011).

In nature, BAV can be detected and isolated from pigs, cattle, and ticks (Liu et al. 2010; Wang et al. 2011). To date, BAV isolates have been obtained from 10 mosquito species in three genera (Culex tritaeniorhynchus, Culex pipiens pallens, Culex annulus, Culex pseudovishnui, Culex modestus, Anopheles sinensis, Aedes vagus, Aedes albopictus, Aedes vexans, and Aedes dorsalis).

Phylogenetic analysis of BAV, according to segment 12, divides the virus strains into two different groups according to their geographic origin: isolates from China and Vietnam are included in group $\mathrm{A}$, and the strains from Indonesia are in group B (Liu et al. 2010, 2016).

BAV is suspected to be an encephalitis-causing pathogen in humans. The clinical symptoms of BAV infection are inflammation of the brain and fever, which is similar to JE. A large-scale sero-survey of patients supposed to have had JE or viral encephalitis was conducted in several 
provinces in China. In this survey, the indirect enzyme linked immunosorbent assay (ELISA) results indicated that the positive rate of anti-BAV IgM antibodies was $11.4 \%$. However, no fourfold or greater BAV specific antibody response was detected by neutralization test in serum from the acute or convalescent phase of illness (Tao and Chen 2005). Further investigation of the association between BAV and human diseases should be conducted (Liu et al. 2011).

\section{Liaoning virus (LNV)}

LNV is a member of the genus Seadornavirus within the family Reoviridae, which is composed of 12 segments of dsRNA. LNV was first obtained from Aedes dorsalis mosquitoes in Liaoning province in China in 1997 (strains LNV-NE9712 and LNV-NE9731) (Attoui et al. 2006). Subsequently, LNV isolates from mosquitoes have been obtained from many regions in China, such as Xinjiang, Qinghai, Beijing, Shanxi, and Gansu, and from several mosquito species including Aedes dorsalis, Aedex caspius, Aedes flavidorsalis, Culex modestus, Culex pipiens, and Culex spp.. (Li et al. 2010; Liu et al. 2011; Lu et al. 2011b; Lv et al. 2012). Currently, all of the reported LNV strains were isolated from China.

LNV can replicate in various mammalian cells and cause viremia and hemorrhage in mice, suggesting LNV maybe pathogenic to humans or animals (Attoui et al. 2006). However, there has been no confirmed report of human disease as a result of LNV in China.

\section{Yunnan orbivirus (YNOV)}

YUOV is a newly identified member of the genus $\mathrm{Or}$ bivirus within the family Reoviridae. The viral genome is composed of 10 segments with conserved terminal sequences (Attoui et al. 2005a; Liu et al. 2011). It was first isolated in 1999 from Culex tritaeniorhynchus in Lanchang County in Yunnan, China. Its presence has so far been reported in China, Australia, and Peru (Attoui et al. 2005a, 2009; Zhang and Liang 2012).

In recent years, six strains of YOUV have been isolated from Culex tritaeniorhynchus in the China-Myanmar-Laos border area (Wang et al. 2011). Sero-surveys have demonstrated YUOV IgM and IgG antibodies in febrile patients from the China-Myanmar-Laos border area, giving evidence of YUOV infection in the area.

\section{Tibet orbivirus (TIBOV)}

TIBOV represents the second orbivirus isolated from mosquito specimens in China. TIBOV (strain XZ0906) was first isolated from a pool of Anopheles maculatus mosquitoes in Tibet, China in 2009 (Li M et al. 2014). Subsequently, TIBOVs were isolated from Culicoides spp., Culex fatigan, or Culex tritaeniorhynchus mosquitoes collected from Yunnan or Guangdong (Lei et al. 2015; Xing et al. 2017). TIBOV could replicate in C6/36 and BHK-21 cells and cause CPE. Currently, it is unclear whether TIBOV can infect either humans or animals. Further studies should be worked for serological survey to define potential human and animal exposures to TIBOV.

\section{Togaviridae}

\section{Chikungunya virus (CHIKV)}

CHIKV is a member of the genus Alphavirus and the family Togaviridae (Pialoux et al. 2007). The virus was first isolated in Tanzania in 1952, and since then CHIKV has spread to Asia, Africa, the Americas, and the areas surrounding the Indian and Pacific Oceans. In China, CHIKV was first isolated from the serum of a patient in Yunnan in 1987 (Huang et al. 1998). Based on the CHIKV E-gene, the virus has been phylogenetically classified into three distinct groups: the Asian genotype, the West African genotype, and the East/Central/Southern African (ECSA) genotype (Pialoux et al. 2007).

The main vectors for CHIKV are Aedex aegypti and Aedex albopictus mosquitoes, the same mosquitoes that transmit DENV (Pialoux et al. 2007). Other Aedes species are sensitive to experimental CHIKV infection, but their role in field transmission has not yet been shown.

Human beings are the known natural hosts of CHIKV. Serological evidence suggests that non-human primates, some rodents and birds, and other vertebrate species may serve as reservoir hosts in nature (McIntosh et al. 1964; Pialoux et al. 2007; Filipe and Pinto 1969; Sam et al. 2015). Recently, the experimental infection of 12 mammalian species and nine avian species indicated that some bats and rodents may serve as reservoir hosts of CHIKV; however, various domestic and wild animal species, including birds, are unlikely to be reservoirs of CHIKV in nature (Bowen et al. 2016).

The most common symptoms of CHIKV infection in humans are fever and joint pain; other symptoms may include headache, rash, nausea, and vomiting. Currently, there is no licensed vaccine or antiviral drug available for CHIKV infection. Although several sporadic cases of nonindigenous CHIKV infection have been documented in China, no outbreak was reported prior to the year 2010. For instance, the first imported sporadic CHIKV infection was reported in Xishuangbanna, Yunnan, in 1987 (Huang et al. 1998). Four imported cases of CHIKV infection were detected in Guangdong Province, in travelers returning from Sri Lanka and Malaysia in 2008 (Zheng et al. 2010). 
One imported case of CHIKV infection was reported in Zhejiang in 2012 (Sun et al. 2013). The first outbreak of chikungunya fever, with 129 laboratory-confirmed cases, was reported in Guangdong in 2010 (Zhang et al. 2012; Wu et al. 2012). The virus in this outbreak belonged to the CES genotype. This outbreak was considered a local outbreak of chikungunya fever caused by an imported case, although the source is unclear (Butt et al. 2014; Li et al. 2012; Lu X et al. 2014; Zhang et al. 2012).

\section{Getah virus (GETV)}

GETV is a member of the genus Alphavirus, family Togaviridae. GETV can cause disease in horses and pigs. It has not been linked to causing disease to humans. It was first isolated from Culex gelidus mosquitoes from Malaysia in 1955. Subsequently, GETV has been isolated in various countries such as Japan, the Philippines, the Republic of Korea, India, and China (Brown and Timoney 1998; Nemoto et al. 2016; Seo et al. 2012; Zhai et al. 2008a). Recent isolates of GETV in Russia, Mongolia, and China indicate a change in the world distribution in terms of reemerging GETV (Zhai et al. 2008a).

In China, GETV was first (strain M1) isolated from Culex mosquitoes in Hainan province in 1964. Since then, various GETV isolates have been found in different mosquito species including Aedex vexans, Armigeres obturbans, Armigeres subalbatus, Culex spp. and unidentified mosquitoes in Hebei, Yunnan, Shanghai, Gansu, and Shanxi during the years 2002-2012, which indicates that GETV is distributed widely in China (Li et al. 2017; Liu et al. 2011; Wang et al. 2011; Zhai et al. 2008a; Zheng et al. 2015). The full-length sequences of the Chinese GETV isolates, South Korean GETV isolate, and Sagiyama virus (SAGV) (Japanese isolate) showed that these viruses exhibit high identity, and up to $5.5 \%$ amino acid sequence divergence was calculated between the original Malaysian isolate of GETV and the Chinese isolates (Zhai et al. 2008a). Neutralizing antibodies to GETV have been identified in serum samples from humans, horses, and pigs in Hainan province in China (Li et al. 1992).

\section{Ross River virus (RRV)}

RRV is a member in the genus Alphavirus, family Togaviridae, which can cause polyarthritis and arthralgias. RRV was first isolated from Aedes vigilax captured in the Australian Ross River region in 1959 (Doherty et al. 1968). RRV is widely distributed in the Pacific region (such as Fiji, Papua New Guinea, Cook Islands) and Australia (Harley et al. 2001; Klapsing et al. 2005; Rosen et al. 1981; Russell 2002; Scrimgeour et al. 1987; Yu et al. 2014).
In China, currently there is only one RRV isolate (strain $\mathrm{HBb} 17$ ) reported, which was isolated from brain tissue of bat in Hainan province. Experimental infection showed that $\mathrm{HBb} 17$ could replicate in mosquitoes and cause mice to die (Zhao et al. 1997). RRV-specific IgG antibodies were detected as positive in serum samples of healthy individuals and rats in Hainan province by immunofluorescence assay (IFA) in 1993 (Zhao et al. 1997). In addition, a serosurvey for viral encephalitis patients and healthy individuals during 2005-2008 in Guizhou indicated there was RRV infection in this region (Ye et al. 2012). However, no survey for the RRV prevalence in mosquitoes collected in China has been reported.

\section{Sindbis virus (SINV)}

SINV is a member of the western equine encephalomyelitis complex and the prototype species of the genus Alphavirus in the family Togaviridae (Laine et al. 2004). SINV (strain Eg339) was first isolated from Culex univittatus mosquitoes collected in Sindbis village in Egypt in 1952 (Taylor et al. 1955). SINV is widely distributed in the world, and strains are divided into three genotypes: Paleoarctic/ Ethiopian (P/E), Oriental/Australian (O/A), and Western/ Australian (W/A) (Taylor et al. 1955).

The first SINV (strain YN87448) in China was isolated in 1986 from the blood of a patient with fever in Yunnan Province (Zhou et al. 1999). To date, only four SINV isolates have been reported in China, three from YunnanYN87448, Sindbis-IMB (1992), and MX10 (2005)—and one from Xinjiang (Liang et al. 2000; Wang et al. 2008, 2011; Zhou et al. 1999). Phylogenetic analysis suggests that YN87448, Sindbis-IMB, and XJ-160 belong to the $\mathrm{P} / \mathrm{E}$ genotype and $\mathrm{XJ}-160$ is clustered in a separate clade. MX10 belongs to the O/A genotype (Liu et al. 2011; Zhang and Liang 2012).

SINV is maintained in nature through an avian-mosquito transmission cycle; the main vectors are Culex spp. and Culiseta spp. mosquitoes. Occasionally, humans and other vertebrates are infected (Kurkela et al. 2008; Laine et al. 2004). SINV infection causes fever, rash, arthritis, and on rare occasions encephalitis in humans, and the clinical infections are reported mainly in northern Europe and South Africa (Adouchief et al. 2016; Kurkela et al. 2008). In China, a sero-survey study demonstrated SINV-specific antibodies ( $\operatorname{IgG})$ detected in healthy individuals or patients with unknown fever, encephalitis, and animals (dogs, foxes, rabbits) in Yunnan, Hainan, Xijiang, Guangdong, and Fujian. This indicates that SINV might be causing fever and viral encephalitis in China (Liu et al. 2011; Zhang and Liang 2012). 


\section{Mosquito-Specific Viruses}

\section{Flaviviridae}

\section{Chaoyang virus (CHAOV)}

CHAOV is a newly recognized ISV of the genus Flavivirus in the family Flaviviridae. Currently, there is no evidence to suggest a role for $\mathrm{CHAOV}$ in animal or human disease. $\mathrm{CHAOV}$ was first isolated (strain Deming) from $A$. vexans in Chaoyang city in Liaoning, China, in 2008 (Liu et al. 2011; Wang ZS et al. 2009). Currently, the isolation of $\mathrm{CHAOV}$ has only been reported in China and the Republic of Korea. An unknown flavivirus (ROK144), which was isolated from Aedex vexans nipponii collected in 2003 in the Republic of Korea, was subsequently determined to be CHAOV (Lee et al. 2013). Phylogenetic analysis with other flaviviruses showed that $\mathrm{CHAOV}$ should be grouped in the same clade as the insect-specific flaviviruses, Lammi virus (LAMV) and Donggang virus (DGV) (Takhampunya et al. 2014). In China, other strains of CHAOV (BeiBei and HLD115) were isolated in 2008 and 2010, respectively. CHAOV Deming strain was shown to induce cytopathic effect (CPE) in C6/36 cells, but cannot replicate in vertebrate cell lines such as baby hamster kidney (BHK), primary duck, primary chicken, and Vero cells (Lee et al. 2013; Liu et al. 2011; Takhampunya et al. 2014).

\section{Culex flavivirus (CxFV)}

$\mathrm{CXFV}$ is an ISV of the genus Flavivirus, family Flaviviridae. It was first isolated in 2003 in Japan from Culex pipiens and Culex tritaeniorhynchus (Hoshino et al. 2007). Subsequently, the virus has been isolated in Asia, Africa, and America (Cook et al. 2009; Wang et al. 2012; Kim et al. 2009; Machado et al. 2012). Phylogenetic analysis based on the $E$ gene of $\mathrm{CxFVs}$ indicates that they can be divided into two distinct genotypes. $\mathrm{CxFV}$ (strain SDDM06-11) was first isolated from Culex pipiens mosquitoes collected in Shandong, China, in 2006 (Huanyu et al. 2012). A larger survey for the distribution and phylogenetic analysis of $\mathrm{CxFV}$ in China was conducted during 2004-2012 (Liang et al. 2015). The result showed 29 (29/ 871 pools) RNAs from Culex pipiens, Culex tritaeniorhynchus, Anopheles sinensis, and Culex spp. tested positive for $\mathrm{CxFV}$. In addition, six $\mathrm{CxFV}$ strains were also isolated from Culex species from Shandong, Henan, and Shaanxi. Phylogenetic analysis of the E gene indicated that the Chinese strains formed a robust subgroup of genotype 1, together with viruses from the United States and Japan (Liang et al. 2015). In 2011, new CxFVs were isolated in Liaoning. In addition, Zuo et al. reported the isolation of
CxFV in Yunnan during 2007-2010. In this study, 11 isolates for YNCxFV were obtained, 10 were from Culex tritaeniorhynchus and one was from Anopheles sinensis. The strains of YNCXFV were most similar to Quang Binh virus (QBV) VN180 isolated from Vietnam (Zuo et al. 2014).

\section{Mesoniviridae}

Mesoniviruses are widely distributed in different geographic regions and have a large host range of mosquito species (Lauber et al. 2012; Thuy et al. 2013).

\section{Nam Dinh virus (NDiV)}

$\mathrm{NDiV}$ is a member of the genus Alphamesonivirus within the newly established family Mesoniviridae. NDiV has been successfully isolated from various mosquito species including Culex vishnui, Culex tritaeniorhynchus, Culex pipiens quinquefasciatus, and Aedes albopictus in Vietnam and the United States. NDiV was first isolated (strain SZ11706Z) in China from samples of Culex pipiens quinquefasciatus in Shenzhen, Guangdong, in 2011 (Zhou et al. 2017). Phylogenetic analysis indicated that the NDiV-CHN strain (SZ11706Z) is closely related to the NDiV-VIE strain (02VN178) isolated from Culex tritaeniorhynchus in Vietnam. NDiV-CHN was grouped into the type species Alphamesonivirus 1, which is represented by NDiV and Cavally virus (CavV) (Zhou et al. 2017).

\section{Yichang virus (YCV)}

YCV is a novel mosquito virus within the family Mesoniviridae. It was originally isolated from Culex spp. mosquitoes in Hubei, China, in 2014, and the prevalence of the YCV sequence in mosquitoes collected from Hubei was $16.5 \%$. YCV has the largest genome size in the family Mesoniviridae, and phylogenetic analyses indicate it belongs to an unassigned genus (Wang et al. 2017).

\section{Parvoviridae}

\section{Culex pipiens pallens densovirus (CppDNV)}

CppDNV belongs to the genus Brevidensovirus within the family Parvoviridae. CppDNV was first isolated from wild-caught adult female Culex pipiens pallens mosquitoes in Liaoning, China, in 2000 (Zhai et al. 2008b). The virus has subsequently been isolated from several species of mosquitoes, including Culex pipiens quinquefasciatus, Culex tritaeniorhynchus, and Anopheles sinensis, and other mosquitoes collected in various provinces of China such as Yunnan, Qinghai, Shanxi, and Inner Mongolia (Cao YX 


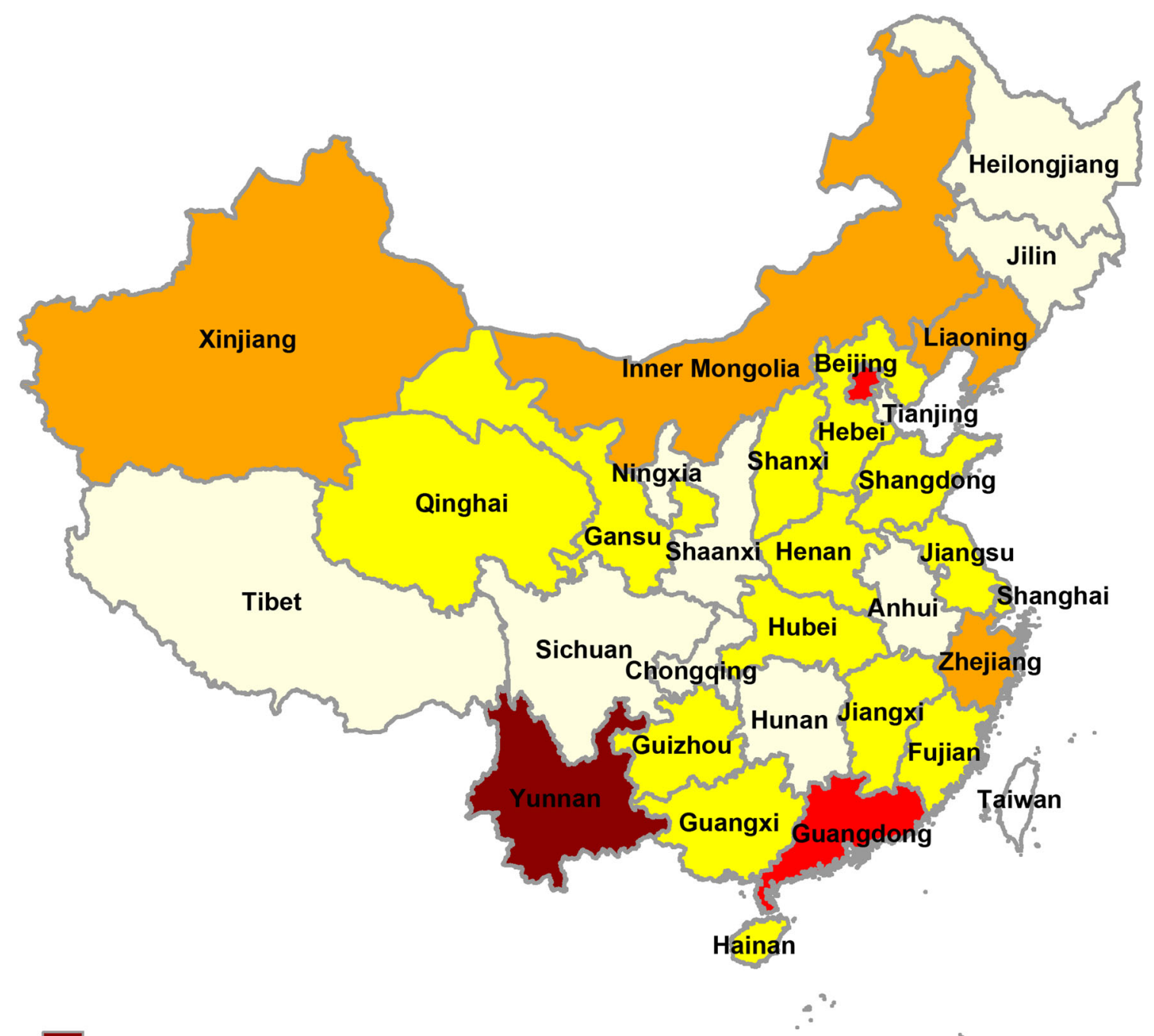

13 types

7 or 8 types

5 or 6 types

3 or 4 types

1 or 2 types

Fig. 1 Distribution of mosquito-associated viruses across mainland China. There are 24 types of mosquito-associated viruses (Table 1) obtained from mosquitoes in different regions of China. The

et al. 2011; Feng et al. 2014; Li et al. 2010; Zhai et al. 2008b; Zheng et al. 2015). Currently, no isolates of CppDNV have been reported outside China. Analysis of the phylogenetic relationships and the genome organization of CppDNV clearly showed that this virus clustered with the species Aedes aegypti densovirus (AaeDNV) and represented a novel variant of this species (Zhai et al. 2008b). mosquito-associated viruses are highly prevalent in the regions of Yunnan, Beijing, Guangdong.

\section{Reoviridae}

Kadipiro virus (KDV)

KDV, which was once classified as coltivirus JKT-7075, belongs to the genus Seadornavirus within the family Reoviridae (Attoui et al. 2000). KDV was first reported in Indonesia, and subsequently found in China. Five strains of $\mathrm{KDV}$, which can cause CPE in C6/36 cells, were isolated from Culex tritaeniorhynchus, Anopheles sinensis, and 
Armigeres obturbans in northwestern Yunnan province in China in 2005 (Liu et al. 2011; Sun et al. 2009a, b).

\section{Mangshi virus (MSV)}

MSV is a newly discovered virus in the genus Seadornavirus of the family Reoviridae and phylogenetically close to BAV. The virus can cause CPE in C6/36 cells but not in mammalian BHK-21 or Vero cells. It was first isolated (strain DH13M041) from one pool of mosquitoes (Culex tritaeniorhynchus) collected in Mangshi City, Dehong Prefecture, southwest of Yunnan in China in 2013 (Wang J et al. 2015). Currently, there are no reports of MSV outside China.

\section{Summary}

The relative distribution of mosquito-associated viruses in China is shown in Fig. 1. A high prevalence of mosquitoassociated viruses exists in the regions of Yunnan, Beijing, Xinjiang, Inner Mongolia, Liaoning, Zhejiang, and Guangdong. The major viruses in high-incidence areas include DENV, JEV, and TMUV (Table 1). In addition, many mosquito-associated virus sequences such as Wuhan mosquito virus, Xinzhou mosquito virus, Zhejiang mosquito virus, Zhee mosquito virus, Wutai mosquito virus, Culex tritaeniorhynchus rhabdovirus, etc., belonging to various viral genera were found by deep sequencing of Chinese mosquito samples from Hubei and Zhejiang in recent studies, which suggests that more extensive cell culture efforts are highly likely to yield additional viruses (Li et al. 2015; Shi et al. 2015, 2016). With the current global warming challenge that is greatly influencing world climatic conditions, unintentional transfer of infected vectors, frequent human migration, rapid urbanization, and widespread deforestation, coupled with new technologies such as deep sequencing, the number of mosquito viruses discovered might increase greatly in China. In the future, we recommend that: (1) surveillance of mosquito-associated viruses, vectors, and hosts, especially viruses that can cause human diseases, should be continuous and be highly intensified; (2) as the association of some of the mosquito viruses such as BAV, YNOV, SINV, and TAHV to human diseases still remain unclear, further pathogenicity investigation studies should be conducted; and (3) in order to reveal why some mosquito-borne viruses possess the ability to infect and cause disease in humans, comparative studies between mosquito-specific viruses and medically important mosquito-borne viruses should be conducted.
Acknowledgements This work is supported by the Ministry of Science and Technology of China (Science and Technology Basic Work Program 2013FY113500).

\section{Compliance with Ethical Standards}

Conflict of interest The authors declare that they have no conflict of interest.

Animal and Human Rights Statement This article does not contain any studies with human or animal subjects performed by any of the authors.

Open Access This article is distributed under the terms of the Creative Commons Attribution 4.0 International License (http://creative commons.org/licenses/by/4.0/), which permits unrestricted use, distribution, and reproduction in any medium, provided you give appropriate credit to the original author(s) and the source, provide a link to the Creative Commons license, and indicate if changes were made.

\section{References}

Adouchief S, Smura T, Sane J, Vapalahti O, Kurkela S (2016) Sindbis virus as a human pathogen-epidemiology, clinical picture and pathogenesis. Rev Med 26:221-241

Attoui H, Billoir F, Biagini P, de Micco P, de Lamballerie X (2000) Complete sequence determination and genetic analysis of Banna virus and Kadipiro virus: proposal for assignment to a new genus (Seadornavirus) within the family Reoviridae. J Gen Virol 81:1507-1515

Attoui H, Mohd Jaafar F, Belhouchet M, Aldrovandi N, Tao S, Chen B, Liang G, Tesh RB, de Micco P, de Lamballerie X (2005a) Yunnan orbivirus, a new orbivirus species isolated from Culex tritaeniorhynchus mosquitoes in China. J Gen Virol 86:3409-3417

Attoui H, Mohd Jaafar F, de Micco P, de Lamballerie X (2005b) Coltiviruses and seadornaviruses in North America, Europe, and Asia. Emerg Infect Dis 11:1673-1679

Attoui H, Jaafar FM, Belhouchet M, Tao S, Chen B, Liang G, Tesh RB, de Micco P, de Lamballerie X (2006) Liao ning virus, a new Chinese Seadornavirus that replicates in transformed and embryonic mammalian cells. J Gen Virol 87:199-208

Attoui H, Mendez-lopez MR, Rao S, Hurtado-Alendes A, LizarasoCaparo F, Jaafar FM, Samuel AR, Belhouchet M, Pritchard LI, Melville L, Weir RP, Hyatt AD, Davis SS, Lunt R, Calisher CH, Tesh RB, Fujita R, Mertens PPC (2009) Peruvian horse sickness virus and Yunnan orbivirus, isolated from vertebrates and mosquitoes in Peru and Australia. Virology 394:298-310

Bialonski A, Günther S, Jöst H, Schmidt-Chanasit J, Schmetz C, Becker N (2011) Isolation and phylogenetic analysis of Batai Virus, Germany. Am J Trop Med Hyg 84:241-243

Bogoch II, Brady OJ, Kraemer MUG, German M, Creatore MI, Kulkarni MA, Brownstein JS, Mekaru SR, Hay SI, Groot E, Watts A, Khan K (2016) Anticipating the international spread of Zika virus from Brazil. Lancet 387:335-336

Bolling B, Weaver S, Tesh R, Vasilakis N (2015) Insect-specific virus discovery: significance for the arbovirus community. Viruses 7:4911-4928 
Bowen RA, Bosco-Lauth AM, Nemeth NM, Kohler DJ (2016) Viremia in North American mammals and birds after experimental infection with chikungunya viruses. Am J Trop Med Hyg 94:504-506

Briese T, Bird B, Kapoor V, Nichol ST, Lipkin WI (2006) Batai and Ngari viruses: $m$ segment reassortment and association with severe febrile disease outbreaks in East Africa. J Virol 80:5627-5630

Brown CM, Timoney PJ (1998) Getah virus infection of Indian horses. Trop Anim Health Prod 30:241-252

Butt AM, Nasrullah I, Tong YG (2014) Genome-wide analysis of codon usage and influencing factors in chikungunya viruses. PLoS ONE 9:e90905

Cao YX, Fu SH, Tian ZF, Lu Z, He Y, Wang HY, Wang JL, Guo WD, Tao B, Liang GD (2011) Distribution of mosquitoes and mosquito-borne arboviruses in Inner Mongolia, China. Vector Borne Zoonotic Dis 11:1577-1581

Cao ZZ, Zhang C, Liu YH, Ye WC, Han JW, Ma GM, Zhang DD, Xu F, Gao XH, Tang Y, Shi SH, Wan CH, Zhang C, He B, Yang MJ, Lu XH, Huang Y, Diao YX, Ma XJ, Zhang DB (2011) Tembusu virus in ducks, China. Emerg Infect Dis 17:1873-1875

Chancey C, Grinev A, Volkova E, Rios M (2015) The global ecology and epidemiology of West Nile virus. Biomed Res Int 2015:376230

Chen J, Lu HZ (2016) Yellow fever in China is still an imported disease. Biosci Trends 10:158-162

Chen ZH, Liu L, Lv YN, Zhang W, Li JD, Zhang Y, Di T, Zhang S, Liu JY, Li J, Qu J, Hua WH, Li C, Wang P, Zhang QF, Xu YL, Jiang RM, Wang Q, Chen LJ, Wang SW, Pang XH, Liang MF, Ma XJ, Li XW, Wang QY, Zhang FJ, Li DX (2016) A fatal yellow fever virus infection in China: description and lessons. Emerg Microbes Infect 5:e69

Cook S, Moureau G, Harbach RE, Mukwaya L, Goodger K, Ssenfuka F, Gould E, Holmes EC, de Lamballerie X (2009) Isolation of a novel species of flavivirus and a new strain of Culex flavivirus (Flaviviridae) from a natural mosquito population in Uganda. J Gen Virol 90:2669-2678

Deng YQ, Zhao H, Li XF, Zhang NN, Liu ZY, Jiang T, Gu DY, Shi L, He JA, Wang HJ, Sun ZZ, Ye Q, Xie DY, Cao WC, Qin CF (2016) Isolation, identification and genomic characterization of the Asian lineage Zika virus imported to China. Sci China Life Sci 59:428-430

Deng C, Liu S, Zhang Q, Xu M, Zhang H, Gu D, Shi L, He J, Xiao G, Zhang B (2016) Isolation and characterization of Zika virus imported to China using C6/36 mosquito cells. Virol Sin 31:176-179

Doherty RL, Standfast HA, Wetters EJ, Whitehead RH, Barrow GJ, Gorman BM (1968) Virus isolation and serological studies of arthropod-borne virus infections in a high rainfall area of North Queensland. Trans R Soc Trop Med Hyg 62:862-867

Feng Y, Zhang HL, Fu SH, Yang WH, Zhang YZ, Wang PY, Yang J, Liu YH, Dong CL, Li S, Zhang BS, Yin ZL, Dong XQ, Wang HY, Liang GD (2014) Investigation on mosquitoes and mosquito-borne viruses in Dehong prefecture, Yunnan province, 2007 and 2010. Zhonghua Liu Xing Bing Xue Za Zhi 35:528-532 (In Chinese)

Filipe AR, Pinto MR (1969) Survey for antibodies to arboviruses in serum of animals from southern Portugal. Am J Trop Med Hyg $18: 423-426$

Fu X, Wang L, Fang B, Ma R, Zheng Y, Huang S, Zhou P, Cao Z, Tian J, Li S, Zhang G (2016) Import of Rift Valley fever to China: a potential new threat? Virol Sin 31:454-456

Fu S, Song S, Liu H, Li Y, Li X, Gao X, Xu Z, Liu G, Wang D, Tian Z, Zhou J, He Y, Lei W, Wang H, Wang B, Lu X, Liang G (2017) ZIKA virus isolated from mosquitoes: a field and laboratory investigation in China, 2016. Sci China Life Sci 60:1364-1371

Gao XY, Nasci R, Liang GD (2010) The neglected arboviral infections in mainland China. PLoS Negl Trop Dis 4:e624

Gao XY, Liu H, Li MH, Fu SH, Liang GD (2015) Insights into the evolutionary history of Japanese encephalitis virus (JEV) based on whole-genome sequences comprising the five genotypes. Virol J 12:43

Gu W, Jin C, Zhang S, Zhang QF, Li JD, Hang XT, Wang Q, Li C, Liang MF, Li DX (2012) Biological characteristics of dengue virus type 3 isolated from Yiwu, China. Chin J Zoonoses 28:695-699

Harley D, Sleigh A, Ritchie S (2001) Ross river virus transmission, infection, and disease: a cross-disciplinary review. Clin Microbiol Rev 14:909-932

Heilman JM, De Wolff J, Beards GM, Basden BJ (2014) Dengue fever: a Wikipedia clinical review. Open Med 8:e105-e115

Hoshino K, Isawa H, Tsuda Y, Yano K, Sasaki T, Yuda M, Takasaki T, Kobayashi M, Sawabe K (2007) Genetic characterization of a new insect flavivirus isolated from Culex pipiens mosquito in Japan. Virology 359:405-414

Huang WL, Zhang HL, Mi ZQ, Shi HF, Bao MH, Qian XY (1998) Some animals' susceptibility to Yunnan CHIK virus. J Dali Med Coll 7:12-15

Huang WL, Zhang HL, Hou ZL, Mi ZQ, Zi DY (2001) Investigation on Arboviruses Antibodies of Patients with Fever in Xishuangbanna, Yunnan Province. Endem Dis Bull 16:39-42

Huang XY, Ma HX, Wang HF, Du YH, Su J, Li XL, Tang XY, Ma HP, Zu BC, Zhang QH, Chen HM, Xu BL (2014) Outbreak of dengue fever in central China, 2013. Biomed Environ Sci $27: 894-897$

Hubálek Z (2008) Mosquito-borne viruses in Europe. Parasitol Res 103:S29-S43

Huhtamo E, Lambert AJ, Costantino S, Servino L, Krizmancic L, Boldorini R, Allegrini S, Grasso I, Korhonen EM, Vapalahti O, Lanciotti RS, Ravanini P (2013) Isolation and full genomic characterization of Batai virus from mosquitoes, Italy 2009. J Gen Virol 94:1242-1248

Jentes ES, Poumerol G, Gershman MD, Hill DR, Lemarchand J, Lewis RF, Staples JE, Tomori O, Wilder-Smith A, Monath TP (2011) The revised global yellow fever risk map and recommendations for vaccination, 2010: consensus of the informal WHO Working Group on Geographic Risk for yellow fever. Lancet Infect Dis 11:622-632

Jiang SF, Zhang YM, Guo XX, Dong YD, Xing D, Xue RD, Zhao TY (2010) Experimental studies on comparison of the potential vector competence of four species of Culex mosquitoes in China to transmit West Nile virus. J Med Entomol 47:788-790

Jiang S, Wang Z, Guo X, Zhang Y, Li C, Dong Y, Xing D, Zhao T (2014) Infection and dissemination of West Nile virus in China by the potential vector, Culex pipiens pallens. J Vector Ecol 39:78-82

Jing QL, Yang ZC, Luo L, Xiao XC, Di B, He P, Fu CX, Wang M, Lu $\mathrm{JH}$ (2012) Emergence of dengue virus 4 genotype II in Guangzhou, China, 2010: survey and molecular epidemiology of one community outbreak. BMC Infect Dis 12:87

Karabatsos N (1978) Supplement to international catalogue of Arboviruses including certain other viruses of vertebrates. Am J Trop Med Hyg 27:372-440

Kim DY, Guzman H, Bueno R, Dennett JA, Auguste AJ, Carrington CVF, Popov VL, Weaver SC, Beasley DWC, Tesh RB (2009) Characterization of Culex Flavivirus (Flaviviridae) strains isolated from mosquitoes in the United States and Trinidad. Virology 386:154-159 
Klapsing P, MacLean JD, Glaze S, McClean KL, Drebot MA, Lanciotti RS, Campbell GL (2005) Ross River virus disease reemergence, Fiji, 2003-2004. Emerg Infect Dis 11:613-615

Kono Y, Tsukamoto K, Hamid MA, Darus A, Lian TC, Sam LS, Yok CN, Di KB, Lim KT, Yamaguchi S, Narita M (2000) Encephalitis and retarded growth of chicks caused by Sitiawan virus, a new isolate belonging to the genus Flavivirus. Am J Trop Med Hyg 63:94-101

Kurkela S, Rätti O, Huhtamo E, Uzcátegui NY, Nuorti JP, Laakkonen J, Manni T, Helle P, Vaheri A, Vapalahti O (2008) Sindbis virus infection in resident birds, migratory birds, and humans, Finland. Emerg Infect Dis 14:41-47

Lai S, Huang Z, Zhou H, Anders KL, Perkins TA, Yin W, Li Y, Mu D, Chen Q, Zhang Z, Qiu Y, Wang L, Zhang H, Zeng L, Ren X, Geng M, Li Z, Tatem AJ, Hay SI, Yu H (2015) The changing epidemiology of dengue in China, 1990-2014: a descriptive analysis of 25 years of nationwide surveillance data. BMC Med 13:100

Laine M, Luukkainen R, Toivanen A (2004) Sindbis viruses and other Alphaviruses as cause of human arthritic disease. J Intern Med 256:457-471

Lan D, Ji W, Yu D, Chu J, Wang C, Yang Z, Hua X (2011) Serological evidence of West Nile virus in dogs and cats in China. Arch Virol 156:893-895

Lauber C, Ziebuhr J, Junglen S, Drosten C, Zirkel F, Nga PT, Morita K, Snijder EJ, Gorbalenya AE (2012) Mesoniviridae: a proposed new family in the order Nidovirales formed by a single species of mosquito-borne viruses. Arch Virol 157:1623-1628

Lee JS, Grubaugh ND, Kondig JP, Turell MJ, Kim HC, Klein TA, O'Guinn ML (2013) Isolation and genomic characterization of Chaoyang virus strain ROK144 from Aedes vexans nipponii from the Republic of Korea. Virology 435:220-224

Lei W, Guo X, Fu S, Feng Y, Nie K, Song J, Li Y, Ma X, Liang G, Zhou H (2015) Isolation of Tibet orbivirus, TIBOV, from Culicoides Collected in Yunnan, China. PLoS ONE 10:e 0136257

Lei W, Guo X, Fu S, Feng Y, Tao X, Gao X, Song J, Yang Z, Zhou H, Liang $G$ (2017) The genetic characteristics and evolution of Tembusu virus. Vet Microbiol 201:32-41

Li XD, Qiu FX, Yang H, Rao YN, Calisher CH (1992) Isolation of Getah virus from mosquitos collected on Hainan Island, China, and results of a serosurvey. Southeast Asian J Trop Med Public Health 23:730-734

Li WJ, Wang JL, Li MH, Fu SH, Wang HY, Wang ZY, Jiang SY, Wang XW, Guo P, Zhao SC, Shi Y, Lu NN, Nasci RS, Tang Q, Liang GD (2010) Mosquitoes and mosquito-borne Arboviruses in the Qinghai-Tibet Plateau-focused on the Qinghai area, China. Am J Trop Med Hyg 82:705-711

Li MH, Fu SH, Chen WX, Wang HY, Guo YH, Liu QY, Li YX, Luo HM, Da W, Ji DZ, Ye XM, Liang GD (2011) Genotype V Japanese encephalitis virus is emerging. PLoS Negl Trop Dis 5:e1231

Li XF, Jiang T, Deng YQ, Zhao H, Yu XD, Ye Q, Wang HJ, Zhu SY, Zhang FC, Qin ED, Qin CF (2012) Complete genome sequence of a chikungunya virus isolated in Guangdong, China. J Virol 86:8904-8905

Li XL, Fu SH, Liu WB, Wang HY, Lu Z, Tong SX, Li ZX, Nasci RS, Kosoy O, Cui Y, Liang GD (2013) West Nile virus infection in Xinjiang, China. Vector Borne Zoonotic Dis 13:131-133

Li W, Cao Y, Fu S, Wang J, Li M, Jiang S, Wang X, Xing S, Feng L, Wang Z, Shi Y, Zhao S, Wang H, Wang Z, Liang G (2014) Tahyna virus infection, a neglected arboviral disease in the Qinghai-Tibet Plateau of China. Vector-Borne Zoonotic Dis 14:353-357

Li M, Zheng Y, Zhao G, Fu S, Wang D, Wang Z, Liang G (2014) Tibet orbivirus, a novel Orbivirus species isolated from
Anopheles maculatus mosquitoes in Tibet, China. PLoS ONE 9:e88738

Li CX, Shi M, Tian JH, Lin XD, Kang YJ, Chen LJ, Qin XC, Xu J, Holmes EC, Zhang YZ (2015) Unprecedented genomic diversity of RNA viruses in arthropods reveals the ancestry of negativesense RNA viruses. Elife. https://doi.org/10.7554/eLife.05378

Li YY, Fu SH, Guo XF, Lei WW, Li XL, Song JD, Cao L, Gao XY, Lyu Z, He Y, Wang HY, Ren XJ, Zhou HN, Wang GQ, Liang GD (2017) Identification of a newly isolated Getah virus in the China-Laos Border, China. Biomed Environ Sci 30:210-214

Liang GD, Li L, Zhou GL, Fu SH, Li QP, Li FS, He HH, Jin Q, He Y, Chen BQ, Hou YD (2000) Isolation and complete nucleotide sequence of a Chinese Sindbis-like virus. J Gen Virol 81:1347-1351

Liang W, He X, Liu G, Zhang S, Fu S, Wang M, Chen W, He Y, Tao X, Jiang H, Lin X, Gao X, Hu W, Liu Y, Feng L, Cao Y, Yang G, Jing C, Liang G, Wang H (2015) Distribution and phylogenetic analysis of Culex flavivirus in mosquitoes in China. Arch Virol 160:2259-2268

Ling Y, Chen J, Huang Q, Hu Y, Zhu A, Ye S, Xu L, Lu H (2016) Yellow fever in a worker returning to China from Angola, March 2016. Emerg Infect Dis J 22:1317

Liu H, Li MH, Zhai YG, Meng WS, Sun XH, Cao YX, Fu SH, Wang HY, Xu LH, Tang Q, Liang GD (2010) Banna virus, China, 1987-2007. Emerg Infect Dis 16:514-517

Liu H, Gao XY, Liang GD (2011) Newly recognized mosquitoassociated viruses in mainland China, in the last two decades. Virol J 8:68

Liu H, Shao X, Hu B, Zhao J, Zhang L, Zhang H, Bai X, Zhang R, Niu D, Sun Y, Yan X (2014) Isolation and complete nucleotide sequence of a Batai virus strain in Inner Mongolia, China. Virol J 11:138

Liu H, Gao XY, Fu SH, Li MH, Zhai YG, Meng WS, Sun XX, Wang HY, Lyu Z, Shen XX, Cao YX, He Y, Liang GD (2016) Analysis on molecular genetic evolution of Banna virus based on the 12(th) segment. Zhonghua Liu Xing Bing Xue Za Zhi 37:1277-1282 (in Chinese)

Liu J, Sun Y, Shi W, Tan S, Pan Y, Cui S, Zhang Q, Dou X, Lv Y, Li X, Li X, Chen L, Quan C, Wang Q, Zhao Y, Lv Q, Hua W, Zeng $\mathrm{H}$, Chen Z, Xiong H, Jiang C, Pang X, Zhang F, Liang M, Wu G, Gao GF, Liu WJ, Li A, Wang Q (2017) The first imported case of Rift Valley fever in China reveals a genetic reassortment of different viral lineages. Emerg Microbes Infect 6:e4

Lu Z, Lu XJ, Fu SH, Zhang S, Li ZX, Yao XH, Feng YP, Lambert AJ, Ni DX, Wang FT, Tong SX, Nasci RS, Feng Y, Dong Q, Zhai YG, Gao XY, Wang HY, Tang Q, Liang GD (2009) Tahyna virus and human infection, China. Emerg Infect Dis 15:306-309

Lu Z, Fu SH, Wang FT, Nasci RS, Tang Q, Liang GD (2011a) Circulation of diverse genotypes of Tahyna virus in Xinjiang, People's Republic of China. Am J Trop Med Hyg 85:442-445

Lu Z, Liu H, Fu S, Lu X, Dong Q, Zhang S, Tong S, Li M, Li W, Tang Q, Liang G (2011b) Liao ning virus in China. Virol J 8:282

Lu X, Li X, Mo Z, Jin F, Wang B, Huang J, Huang J, Zhao H, Shi L (2014) Chikungunya emergency in China: microevolution and genetic analysis for a local outbreak. Virus Genes 48:15-22

Lu Z, Fu SH, Cao L, Tang CJ, Zhang S, Li ZX, Tusong M, Yao XH, Zhang HL, Wang PY, Wumaier M, Yuan XY, Li MH, Zhu CZ, Fu LP, Liang GD (2014) Human infection with West Nile virus, Xinjiang, China, 2011. Emerg Infect Dis J 20:1421-1423

Lv Z, Fu S, Wang F, Kosoy OL, Nasci RS, Liang G (2011) Investigation of Tahyna virus infection among unknown fever cases in Xinjiang, China. Chin J Virol 27:71-74

Lv X, Jaafar FM, Sun X, Belhouchet M, Fu S, Zhang S, Tong S, Lv Z, Mertens PPC, Liang G, Attoui H (2012) Isolates of Liao Ning virus from wild-caught mosquitoes in the Xinjiang Province of China in 2005. PLoS ONE 7:e37732 
Machado DC, Mondini A, dos Santos SantanaV, Yonamine PTK, Chiaravalloti Neto F, Zanotto PM, Nogueira ML (2012) First identification of Culex flavivirus (Flaviviridae) in Brazil. Intervirology 55:475-483

McIntosh BM, Paterson HE, McGillivray G, De Sousa J (1964) Further studies on the chikungunya outbreak in Southern Rhodesia in 1962. Ann Trop Med Parasitol 58:45-51

Messina JP, Brady OJ, Scott TW, Zou C, Pigott DM, Duda KA, Bhatt S, Katzelnick L, Howes RE, Battle KE, Simmons CP, Hay SI (2014) Global spread of dengue virus types: mapping the 70 year history. Trends Microbiol 22:138-146

Misra UK, Kalita J (2010) Overview: Japanese encephalitis. Prog Neurobiol 91:108-120

Monath TP, Vasconcelos PFC (2015) Yellow fever. J Clin Virol 64:160-173

Nabeshima T, Nga PT, Guillermo P, del Carnen Parquet M, Yu F, Thuy NT, Trang BM, Hien NT, Nam VS, Inoue S, Hasebe F, Morita K (2008) Isolation and molecular characterization of Banna virus from mosquitoes, Vietnam. Emerg Infect Dis 14:1276-1279

Nemoto M, Bannai H, Tsujimura K, Yamanaka T, Kondo T (2016) Genomic, pathogenic, and antigenic comparisons of Getah virus strains isolated in 1978 and 2014 in Japan. Arch Virol 161:1691-1695

O’Guinn ML, Turell MJ, Kengluecha A, Jaichapor B, Kankaew P, Miller RS, Endy TP, Jones JW, Coleman RE, Lee JS (2013) Field detection of Tembusu virus in western Thailand by RTPCR and vector competence determination of select Culex mosquitoes for transmission of the virus. Am J Trop Med Hyg 89:1023-1028

Pepin M, Bouloy M, Bird BH, Kemp A, Paweska J (2010) Rift Valley fever virus (Bunyaviridae: Phlebovirus): an update on pathogenesis, molecular epidemiology, vectors, diagnostics and prevention. Vet Res 41:61

Pialoux G, Gaüzère BA, Jauréguiberry S, Strobel M (2007) Chikungunya, an epidemic arbovirosis. Lancet Infect Dis 7:319-327

Rasmussen SA, Jamieson DJ, Honein MA, Petersen LR (2016) Zika virus and birth defects-reviewing the evidence for causality. N Engl J Med 374:1981-1987

Rosen L, Gubler DJ, Bennett PH (1981) Epidemic polyarthritis (Ross River) virus infection in the Cook Islands. Am J Trop Med Hyg 30:1294-1302

Rossi SL, Ross TM, Evans JD (2010) West Nile virus. Clin Lab Med 30:47-65

Russell RC (2002) Ross River virus: ecology and distribution. Annu Rev Entomol 47:1-31

Sam IC, Chua CL, Rovie-Ryan JJ, Fu JYL, Tong C, Sitam FT, Chan YF (2015) Chikungunya virus in Macaques, Malaysia. Emerg Infect Dis 21:1683-1685

Scrimgeour EM, Aaskov JG, Matz LR (1987) Ross River virus arthritis in Papua New Guinea. Trans R Soc Trop Med Hyg 81:833-834

Seo HJ, Kim HC, Klein TA, Park JY, Cho YS, Cho IS, Kyung SG, Yeh JY (2012) Characterization of recent Getah virus isolates from South Korea. Acta Virol 56:265-267

Shi C, Liu Y, Hu X, Xiong J, Zhang B, Yuan Z (2015) A metagenomic survey of viral abundance and diversity in mosquitoes from Hubei province. PLoS ONE 10:e0129845

Shi M, Lin XD, Tian JH, Chen LJ, Chen X, Li CX, Qin XC, Li J, Cao JP, Eden JS, Buchmann J, Wang W, Xu J, Holmes EC, Zhang YZ (2016) Redefining the invertebrate RNA virosphere. Nature 540:539-543

Shi Y, Zheng K, Li X, Li L, Li S, Ma J, Dai J, Ji J, Yuan S, Lu H, Li J, Sun F, Xu X, Huang J (2017) Isolation and phylogenetic study of Rift Valley fever virus from the first imported case to China. Virol Sin 32(3):253-256
Solomon T, Ni H (2003) Origin and evolution of Japanese encephalitis virus in southeast Asia. J Virol 77:3091-3098

Solomon T, Dung NM, Kneen R, Gainsborough M, Vaughn DW, Khanh VT (2000) Japanese encephalitis. J Neurol Neurosurg Psychiatry 68:405-415

Song S, Li Y, Fu S, Liu H, Li X, Gao X, Xu Z, Liu G, Wang D, Tian Z, Zhou J (2017) Could Zika virus emerge in Mainland China? Virus isolation from nature in Culex quinquefasciatus, 2016. Emerg Microbes Infect 6:e93

Su S, Qiu X, Zhou J (2016) Spread of ZIKV and YFV to China: potential implications. J Infect 73:289-291

Sun XH, Fu SH, Gong Z, Ge J, Meng W, Feng Y, Wang J, Zhai Y, Wang HH, Nasci RS, Tang Q, Liang GD (2009a) Distribution of arboviruses and mosquitoes in Northwestern Yunnan Province, China. Vector-Borne Zoonotic Dis 9:623-630

Sun XH, Meng WS, Fu SH, Feng Y, Zhai YG, Wang JL, Wang HQ, Lv XJ, Liang GD (2009b) The first report of Kadipiro virus isolation in China. Chin J Virol 25:173-177

Sun JM, Lin JF, Yan JY, Fan WZ, Lu L, Lv HK, Hou J, Ling F, Fu T, Chen ZP, Cong LM, Liu QY, Zhang YJ, Chai CL (2011) Dengue virus serotype 3 subtype III, Zhejiang Province, China. Emerg Infect Dis 17:321-323

Sun Y, Yan J, Mao H, Zhang L, Lyu Q, Wu Z, Zheng W, Feng C, Zhang Y (2013) Characterization of the complete genome of chikungunya in Zhejiang, China, using a modified virus discovery method based on cDNA-AFLP. PLoS ONE 8:e83014

Takhampunya R, Kim HC, Tippayachai B, Lee DK, Lee WJ, Chong ST, Kim MS, Lee JS, Klein TA (2014) Distribution and mosquito hosts of Chaoyang virus, a newly reported flavivirus from the Republic of Korea, 2008-2011. J Med Entomol 51:464-474

Tang Y, Gao X, Diao Y, Feng Q, Chen H, Liu X, Ge P, Yu C (2013) Tembusu virus in Human, China. Transbound Emerg Dis 60:193-196

Tang Y, Diao Y, Chen H, Ou Q, Liu X, Gao X, Yu C, Wang L (2015) Isolation and genetic characterization of a Tembusu virus strain isolated from mosquitoes in Shandong, China. Transbound Emerg Dis 62:209-216

Tao S, Chen B (2005) Studies of Coltivirus in China. Chin Med J 118:581-586

Taylor RM, Hurlbut HS, Work TH, Kingston JR, Frothingham TE (1955) Sindbis virus: a newly recognized arthropodtransmitted virus. Am J Trop Med Hyg 4:844-862

Thuy NT, Huy TQ, Nga PT, Morita K, Dunia I, Benedetti L (2013) A new nidovirus (NamDinh virus $\mathrm{NDiV}$ ): its ultrastructural characterization in the C6/36 mosquito cell line. Virology 444:337-342

Wang HY, Takasaki T, Fu SH, Sun XH, Zhang HL, Wang ZX, Hao ZY, Zhang JK, Tang Q, Kotaki A, Tajima S, Liang XF, Yang WZ, Kurane I, Liang GD (2007) Molecular epidemiological analysis of Japanese encephalitis virus in China. J Gen Virol 88:885-894

Wang JL, Zhang HL, Che YC, Wang LC, Ma SH, Liu LD, Liao Y, Li QH (2008) Isolation and complete genomic sequence analysis of a new Sindbis-like virus. Virol Sin 23:31-36

Wang FT, Lv Z, Wang JL, Fu SH, Zhang HL, Wang ZY, Liang GD (2009) Sequencing and analysis of the full coding sequence of Batai virus isolated in China. Chin J Virol 25:83-87

Wang HY, Li YX, Liang XF, Liang GD (2009) Japanese encephalitis in mainland China. Jpn J Infect Dis 62:331-336

Wang ZS, An SY, Wang Y, Han Y, Guo JQ (2009) A new virus of flavivirus: Chaoyang virus isolated in Liaoning Province. Chin Pub Heal 25:769-772

Wang JL, Zhang HL, Sun XH, Fu SH, Wang HQ, Feng Y, Wang HY, Tang Q, Liang GD (2011) Distribution of mosquitoes and 
mosquito-borne arboviruses in Yunnan Province near the ChinaMyanmar-Laos border. Am J Trop Med Hyg 84:738-746

Wang HY, Fu SH, Liu GF, Liu H, Gao XY, Song LZ, Simon R, Xu AQ, Liang GD (2012) Isolation and identification of a distinct strain of Culex Flavivirus from mosquitoes collected in Mainland China. Virol J 9:73

Wang J, Li H, He Y, Zhou Y, Meng J, Zhu W, Chen H, Liao D, Man $Y$ (2015) Isolation and genetic characterization of Mangshi virus: a newly discovered Seadornavirus of the Reoviridae family found in Yunnan Province, China. PLoS ONE 10:e0143601

Wang W, Yu B, Lin XD, Kong DG, Wang J, Tian JH, Li MH, Holmes EC, Zhang YZ (2015) Reemergence and autochthonous transmission of Dengue virus, Eastern China, 2014. Emerg Infect Dis J 21:1670-1673

Wang YJ, Xia H, Zhang B, Liu XY, Yuan ZM (2017) Isolation and characterization of a novel mesonivirus from Culex mosquitoes in China. Virus Res 240:130-139

Wasserman S, Tambyah PA, Lim PL (2016) Yellow fever cases in Asia: primed for an epidemic. Int J Infect Dis 48:98-103

Wu JY, Lun ZR, James A, Chen XG (2010) Dengue fever in mainland China. Am J Trop Med Hyg 83:664-671

Wu D, Wu J, Zhang Q, Zhong H, Ke C, Deng X, Guan D, Li H, Zhang Y, Zhou H, He J, Li L, Yang X (2012) Chikungunya outbreak in Guangdong Province, China, 2010. Emerg Infect Dis J 18:493-495

Xing S, Guo X, Zhang X, Zhao Q, Li L, Zuo S, An X, Pei G, Sun Q, Cheng S, Wang Y, Fan H, Mi Z, Huang Y, Zhang Z, Zhou H, Zhang J, Tong Y (2017) A novel mosquito-borne reassortant orbivirus isolated from Xishuangbanna, China. Virol Sin 32:159-162

Xiong YQ, Chen Q (2014) Epidemiology of dengue fever in China since 1978. J South Med Univ 34:1822-1825 (In Chinese)

Xu PT, Wang YM, Zuo JM, Lin JW, Xu PM (1990) New Orbiviruses isolated from patients with unknown fever and encephalitis in Yunnan province. Chin J Virol 6:27-33

Yan JY, Zhang YJ, Mao HY, Lin JF, Chen JH, Ling F, Wang XY, Lu YY (2010) Diagnosis of a dengue fever outbreak in Yiwu city, Zhejiang province in 2009 and its molecular tracing of the pathogen. Zhonghua Yu Fang Yi Xue Za Zhi 44:1091-1096

Yan P, Zhao Y, Zhang X, Xu D, Dai X, Teng Q, Yan L, Zhou J, Ji X, Zhang S, Liu G, Zhou Y, Kawaoka Y, Tong G, Li Z (2011) An infectious disease of ducks caused by a newly emerged Tembusu virus strain in mainland China. Virology 417:1-8

Yang M, Jiang J, Guo X, Wu C, Zhou H (2015) Epidemiological analysis and investigation of dengue fever in Yunnan province from 2009 to 2014. J Pathog Biol 10:738-742

Ye X, Fu S, Gao X, Zhao S, Liu C, Wang H, Wu S, Liang G (2012) Investigation of infection with Barmah Forest virus and Ross River virus in Guizhou province, China. Chin J Vect Bio Co 23:428-431

Yu W, Mengersen K, Dale P, Mackenzie JS, Toloo GS, Wang X, Tong S (2014) Epidemiologic patterns of Ross River virus disease in Queensland, Australia, 2001-2011. Am J Trop Med Hyg 91:109-118
Zanluca C, Duarte CN, Santos D (2016) Zika virus-an overview. Microbes Infect 18:295-301

Zhai YG, Wang HY, Sun XH, Fu SH, Wang HQ, Attoui H, Tang Q, Liang GD (2008a) Complete sequence characterization of isolates of Getah virus (genus alphavirus, family Togaviridae) from China. J Gen Virol 89:1446-1456

Zhai YG, Lv XJ, Sun XH, Fu SH, Gong ZD, Fen Y, Tong SX, Wang ZX, Tang Q, Attoui H, Liang GD (2008b) Isolation and characterization of the full coding sequence of a novel densovirus from the mosquito Culex pipiens pallens. J Gen Virol 89:195-199

Zhang HL, Liang GD (2012) Arboviruses and arboviral diseases in China. Chin J Vector Biol Control 23:377-380

Zhang QL, He JF, Wu D, Wang ZJ, Zhong XG, Zhong HJ, Ding F, Liu ZQ, Wang SW, Huang ZY, Zhang YH, Ke CW, Yuan DK, Liang WJ, Li DQ, Chen PH (2012) Maiden outbreak of chikungunya in Dongguan city, Guangdong province, China: epidemiological characteristics. PLoS ONE 7:e42830

Zhang FC, Zhao H, Li LH, Jiang T, Hong WX, Wang J, Zhao LZ, Yang HQ, Ma DH, Bai CH, Shan XY, Deng YQ, Qin CF (2014) Severe dengue outbreak in Yunnan, China, 2013. Int J Infect Dis 27:4-6

Zhang Y, Chen W, Wong G, Bi Y, Yan J, Sun Y, Chen E, Yan H, Lou X, Mao H, Xia S, Gao GF, Shi W, Chen Z (2016) Highly diversified Zika viruses imported to China, 2016. Protein Cell 7:461-464

Zhang W, Chen S, Mahalingam S, Wang M, Cheng A (2017) An updated review of avian-origin Tembusu virus: a newly emerging avian Flavivirus. J Gen Virol 98:2413-2420

Zhao C, Jiang L, Yu X, Chen W (1997) Isolation of Ross River virus and its antibody Prevalence in Hainan Province. Chin J Vet Sci 17:241-243

Zhao Y, Li L, Ma D, Luo J, Ma Z, Wang X, Pan Y, Chen J, Xi J, Yang J, Qiu L, Bai C, Jiang L, Shan X, Sun Q (2016) Molecular characterization and viral origin of the 2015 dengue outbreak in Xishuangbanna, Yunnan, China. Sci Rep 6:34444

Zheng K, Li J, Zhang Q, Liang M, Li C, Lin M, Huang J, Li H, Xiang D, Wang N, Hong Y, Huang L, Li X, Pan D, Song W, Dai J, Guo B, Li D (2010) Genetic analysis of chikungunya viruses imported to mainland China in 2008. Virol J 7:8

Zheng Y, Cao Y, Fu S, Cheng J, Zhao J, Dai P, Kong X, Liang G (2015) Isolation and identification of mosquito-borne $A r$ boviruses in Yuncheng city, Shanxi province, 2012. Zhonghua Liu Xing Bing Xue Za Zhi 36:368-373

Zhou G, Liang G, Li L (1999) Complete nucleotide sequence of the nonstructural gene of alphavirus YN87448 strain isolated in China and its relationship to other Sindbis viruses. Zhonghua Shi Yan He Lin Chuang Bing Du Xue Za Zhi 13:314-320

Zhou J, Jin Y, Chen Y, Li J, Zhang Q, Xie X, Gan L, Liu Q (2017) Complete genomic and ultrastructural analysis of a Nam Dinh virus isolated from Culex pipiens quinquefasciatus in China. Sci Rep 7:271

Zuo S, Zhao Q, Guo X, Zhou H, Cao W, Zhang J (2014) Detection of Quang Binh virus from mosquitoes in China. Virus Res 180:31-38 